\title{
The renewable Energy Sector in the European Union - A Statistical Analysis
}

Cristian MARINESCU ${ }^{1}$

Abstract
Increasing the share of energy from renewable sources in total energy consumption
is a permanent concern for the Member States of the European Union.
In this paper we propose to show the present situation of the renewable energy
sector in the European Union, namely a statistical analysis of the gross consumption of
renewable energy at the level of the European Union during $1990-2016$, the evolution of
the share of renewable energy in gross final consumption of energy in the EU 28 between
2004 and 2016 and a presentation of the renewable energy sector in EU28 member states in
2016.

Keywords: renewable energy,energy sources, energy consumption, European Union
JEL clasifications: Q4
DOI: $10.24818 / \mathrm{RMCI} .2019 .1 .52$

\section{Introduction}

In the current context of our continent, characterized by an intense pollution caused mainly by the production of energy, largely through burning of fossil fuels, the production of energy from renewable sources becomes extremely important.

EU renewable energy policies have helped to develop the renewable energy sector, accounting for almost $20 \%$ of total energy consumption in the EU28.

The term "renewable energy" covers all forms of energy that are produced as a result of the energy transfer of energy through different natural renewable processes.

Renewable energy is energy produced from renewable non-fossil sources which, when considered at a human scale, are naturally restored. These include solar, wind, ocean, hydro, geothermal and bioenergy².

\footnotetext{
${ }^{1}$ Cristian Marinescu, Romanian Court of Accounts, Email: cristian.marinescu@ macroeconomie.ro;

${ }^{2}$ Article 2 (a) of Directive 2009/28 / CE on the promotion of the use of energy from renewable sources, issued on 23 April 2009;
} 


\section{The current state of the renewable energy sector in the European Union}

Developing the renewable energy sector has been a priority for the European Union lately by adopting long-term strategies and objectives, and this has resulted in a significant increase in energy consumption from renewable sources.

As can be seen in Chart no. 1, gross energy consumption from renewable sources in the European Union (EU28) tripled between 1990 and 2016, starting from a value of $72,147.1$ thousand tons of oil equivalent (KTOE) as it was in 1990 to 216,617.7 KTOE in 2016.

In order to have a clearer picture of the effect the renewable energy policies and objectives of the European Union have had on the growth of renewable energy consumption, we made a brief analysis of the evolution of renewable energy consumption according to three periods, respectively : 1990-2000, 2000-2010 and 2016-2010, the latter being also the period in which the renewable energy policies established by Directive 2009/28 / CE on the promotion of the use of energy from renewable sources were implemented, which established that $20 \%$ of European Union energy needs to be produced from renewable sources by 2020 .

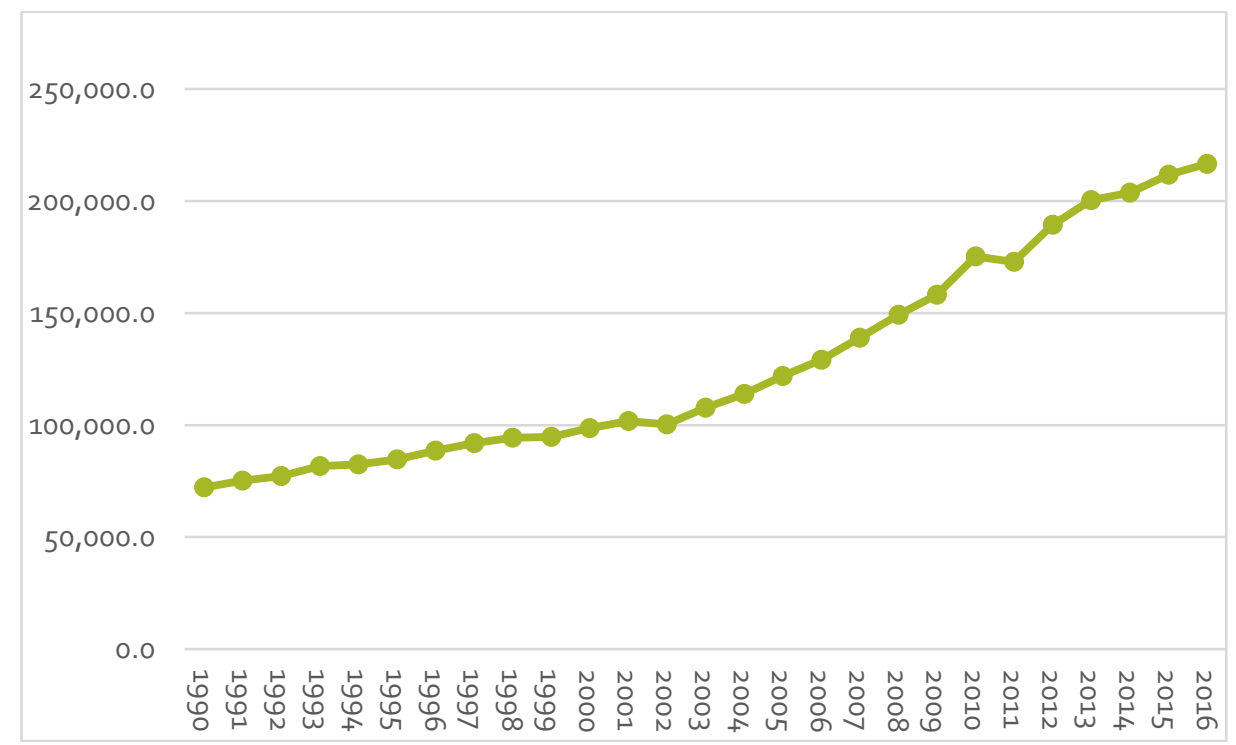

Chart 1 - The evolution of gross renewable energy consumption in the EU28 between 1990 and 2016 (KTOE)

Source: Eurostat 


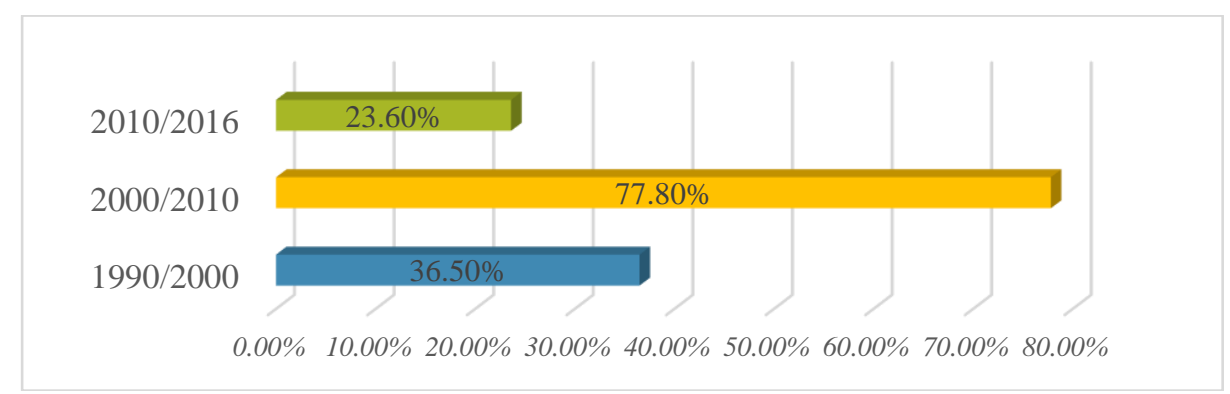

Chart 2 - Evolution of gross renewable energy consumption

in the EU 28 between 1990 and 2016

Source: Own calculations based on Eurostat data

Surprisingly, in the period 2016-2010, gross consumption of renewable energy increased only by $23.6 \%$ (in 2016 compared to 2010), unlike the period 20002010 , when the increase in energy consumption from sources was $77.8 \%$ (Chart 2).

It is true that, in order to have a comparable period, we must see the evolution of renewable energy consumption by 2020 , but if the same trend is followed, renewable energy consumption in the EU 28 in 2020-2010 will not registered in the period 2000-2010, although the new Renewable Energy Directive adopted by the European Parliament on 11 December 2018 (EU Directive 2018/2001) proposes a new "target" on the share of energy from renewable sources consumed in the Union, namely that by 2030 this would represent at least $27 \%$.

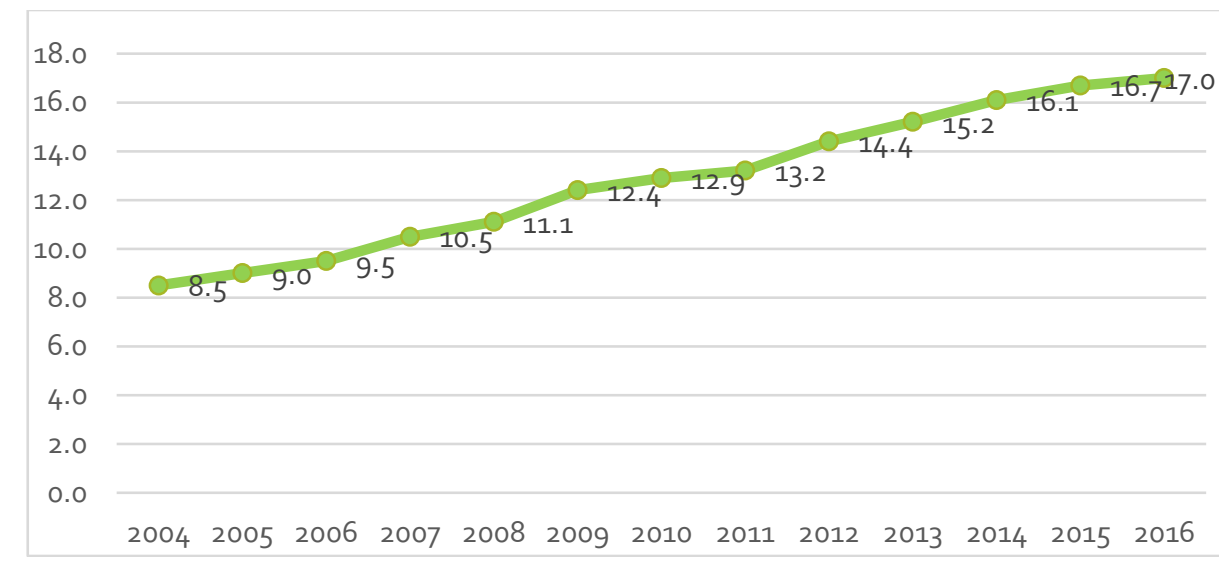

Chart 3 - Evolution of the share of renewable energy in gross final consumption of energy in the EU 28 between 2004 and 2016

Source: Eurostat

Regarding the share of renewable energy in gross final consumption of energy, according to the data available on Eurostat, between 2004 and 2016, it had an ascending evolution, as shown in Chart no. 3. Between 2004 and 2016, the share of renewable energy in gross final energy consumption doubled from $8.5 \%$ (2004) to $17 \%(2016)$.

$54 \quad$ Review of International Comparative Management

Volume 20, Issue 1, March 2019 
s stated above, Directive 2009/28 / CE on the promotion of the use of energy from renewable sources has established that the share of renewable energy in gross final energy consumption should reach $20 \%$ at EU level by 2020 , the most likely target will be achieved, taking into account that at the end of 2016 the share of renewable energy in gross final consumption of energy at EU-28 was 17\%.

The best Member States that have good share of renewable energy in gross final energy consumption are (Graph 4): Sweden (53.8\%), which has a share of renewable energy in gross final energy consumption almost three times higher than the EU average 28, Finland (38.7\%), Latvia (37.2\%), Austria (33.5\%) and Denmark $(32.2 \%)$.

At the opposite end, Luxembourg (5.4\%), Malta and the Netherlands (6\%), Belgium (8.7\%), Cyprus and the United Kingdom (9\%), with the lowest share of renewable energy in the gross final consumption of energy, 3\%) and Ireland (9.5\%).

In chart no. 5 we can see the share of renewable energy forms in total renewable energy consumption in the European Union in 2016. The highest share of biomass energy (bioenergy) represents $65 \%$ of the total renewable energy consumption; hydroelectric power (14\%), wind energy (12\%), solar energy $(6 \%)$ and geothermal energy (3)\%.

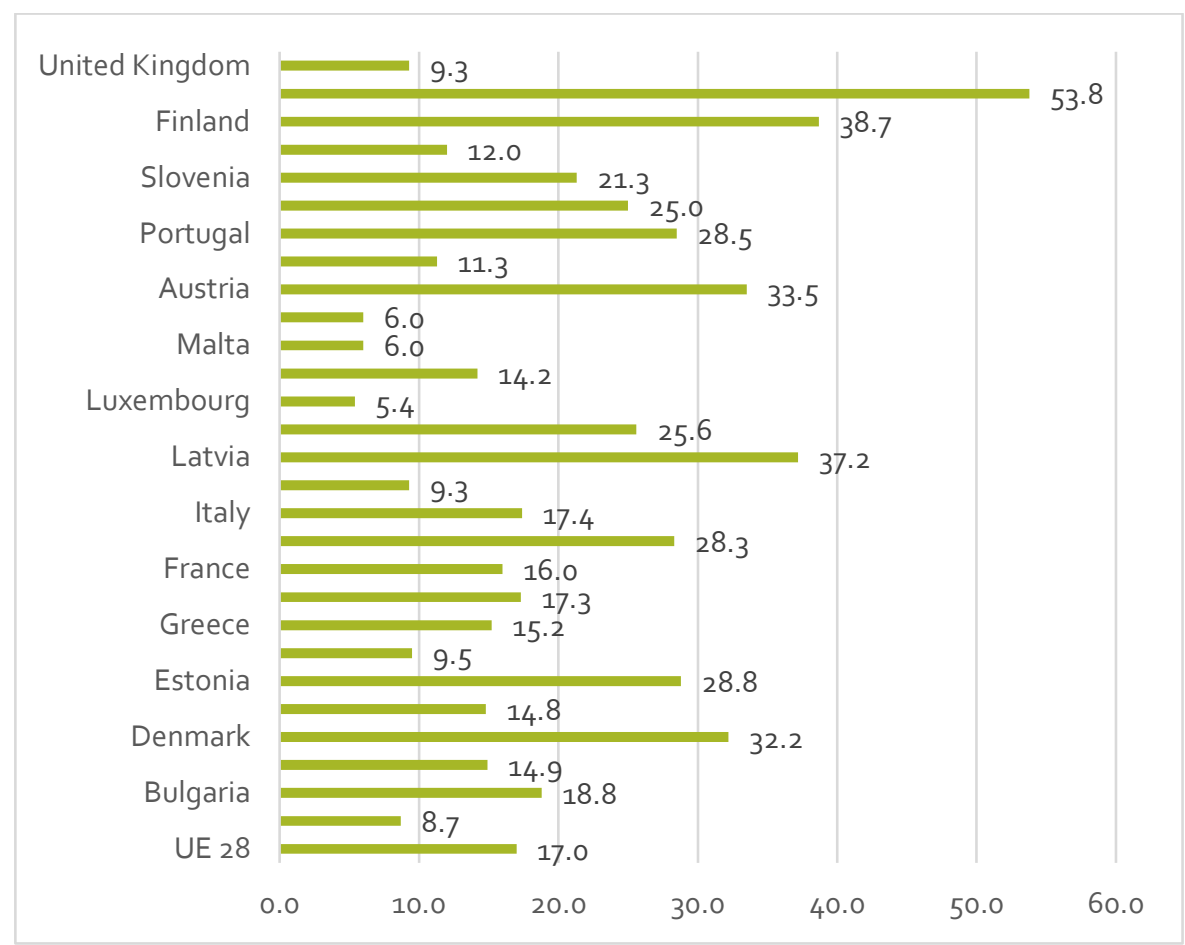

Chart 4 - The share of renewable energy in gross final consumption of energy in 2016 in the Member States

Source: Eurostat 


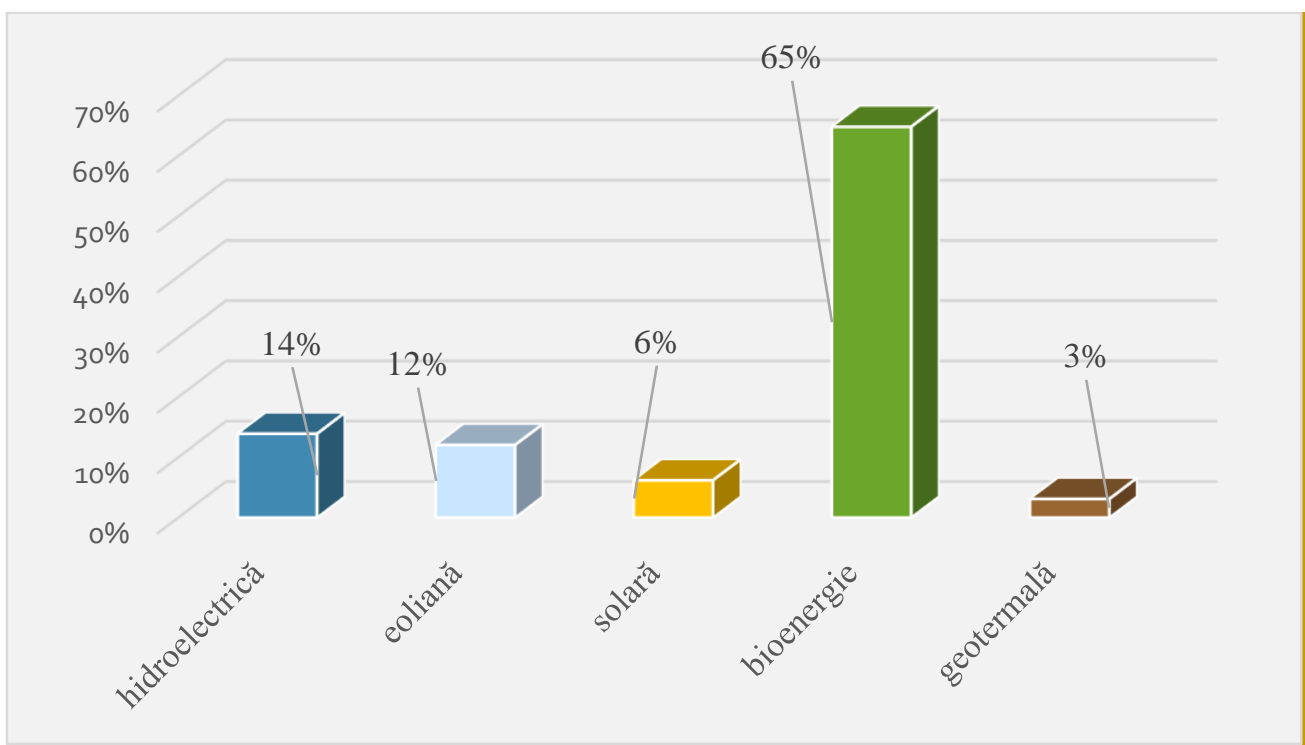

Chart 5 - The share of renewable energy forms in total renewable energy consumption in the EU 28 in 2016

Source: Own calculations based on Eurostat data

The main renewable energy consumers in the EU28 are: Germany (which has the highest renewable energy consumption among EU-28 countries and at the same time was the country with the highest increase in renewable energy consumption in 2016 compared to 1990, almost 8 times, from 5,313.4 thousand TOE in 1990 to 38,915.5 thousand TOE in 2016), France and Italy, and the Member States with the lowest gross domestic consumption of renewable energy are: Malta, Cyprus, Luxembourg, Estonia and Ireland.

In the following, we will present a presentation of the renewable energy sector in the EU28 in terms of renewable forms of energy, taking the 2016 benchmark.

In terms of hydroelectric power production in the European Union in 2016 (Chart no. 6), Sweden recorded the largest hydroelectric power production, followed by Spain, Italy and Austria. At the opposite end, the smallest hydroelectric power production was registered in Malta and Cyprus, which do not produce any hydroelectric energy, as well as in Denmark and Estonia with a production of 1,600 TOE and 3,000 TOE respectively. 


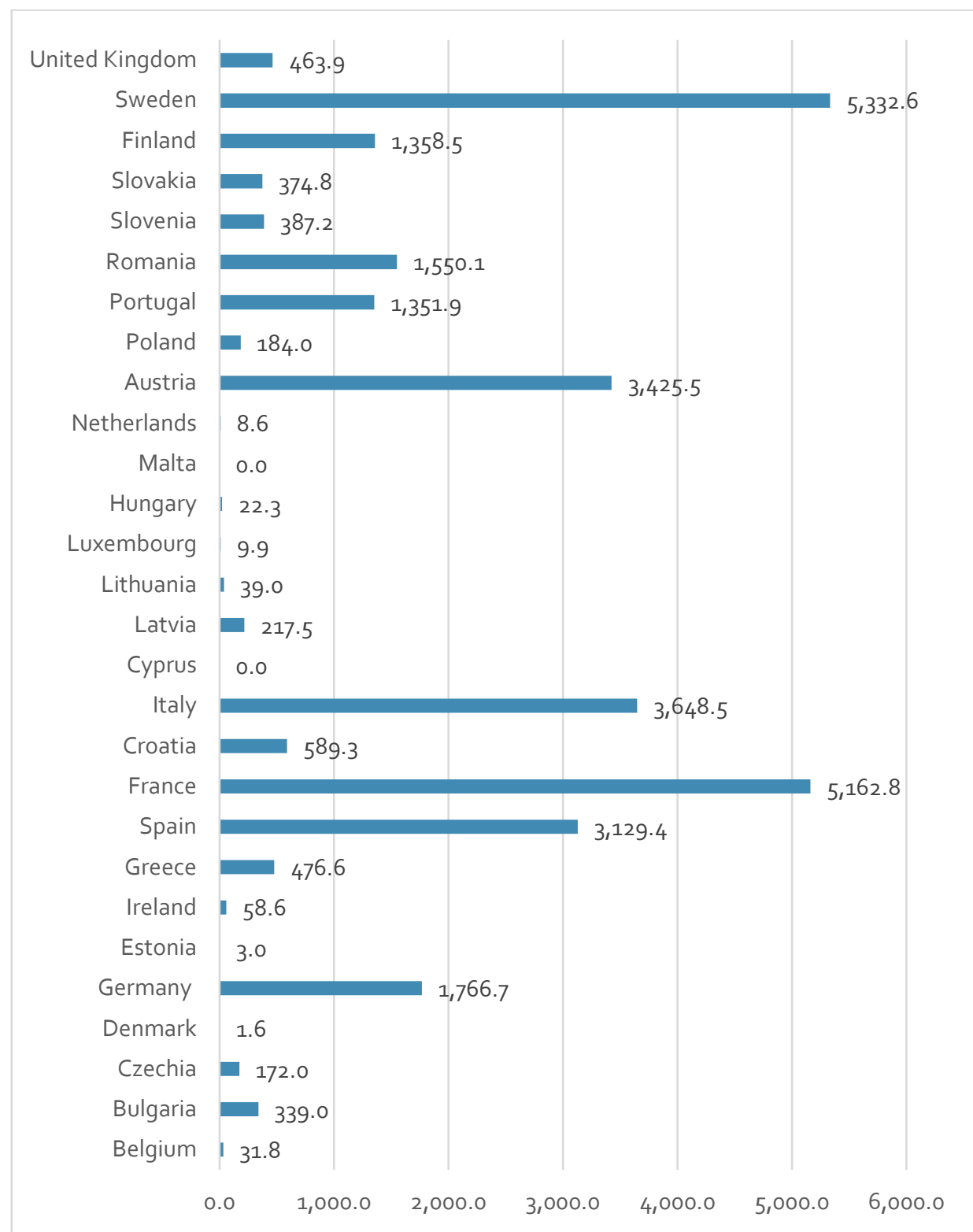

\section{Chart 6 - Gross domestic consumption of hydroelectric energy} in EU28 in 2016 (KTOE)

Source: Eurostat

Regarding to the wind energy production in the European Union in 2016 (chart no. 7), the main wind energy producers are Germany (6,758.2 KTOE), Spain (4.205,2 KTOE) and the United Kingdom (4,205.2 KTOE), and the least energy wind consuming countries are Malta (not producing any wind energy), Slovakia and Slovenia (0.5 KTOE). 


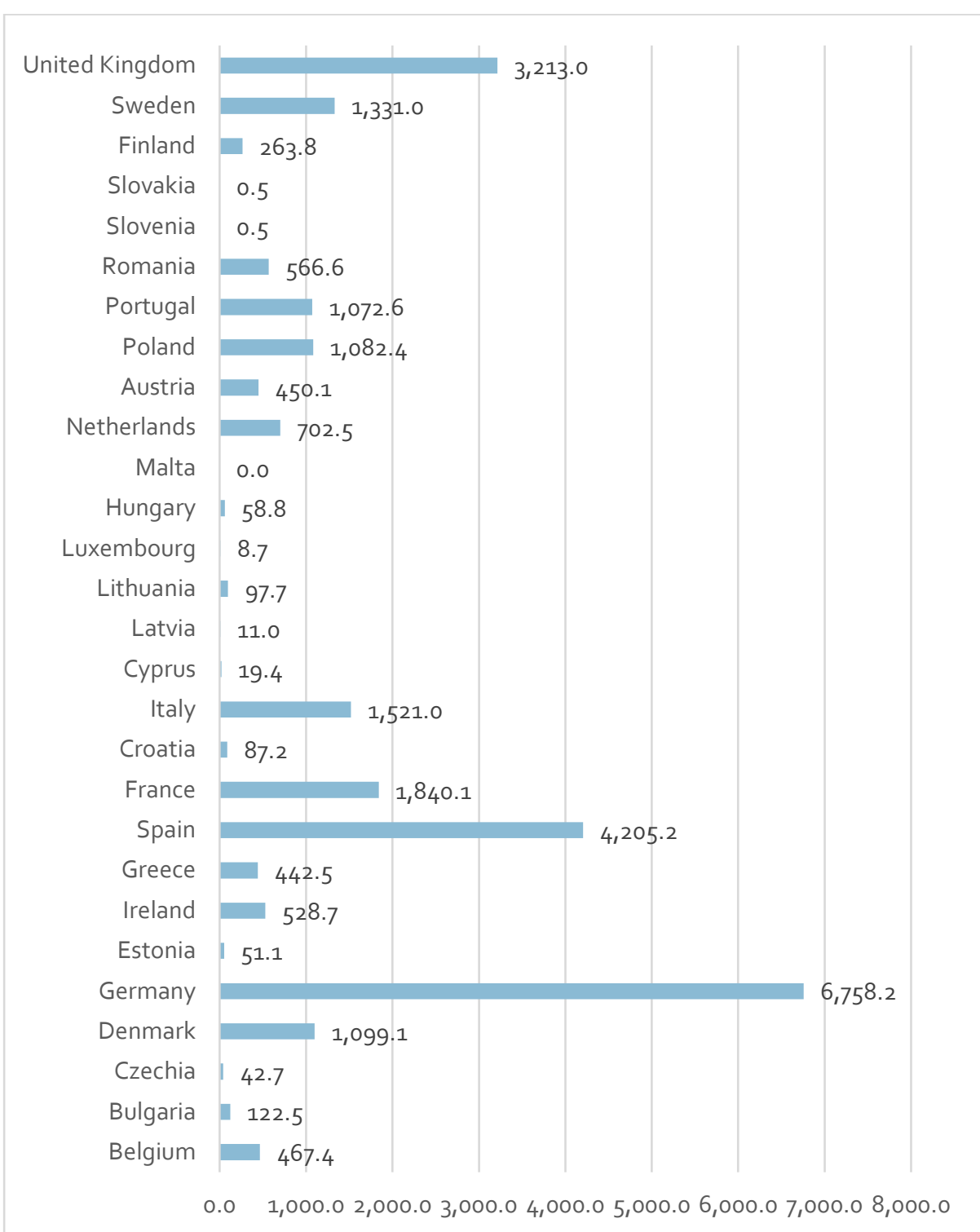

Chart 7 - Gross Domestic consumption of Wind Energy in EU28 in 2016 (KTOE) Source: Eurostat

Regarding to the solar energy production in the European Union in 2016, (chart no. 8), Germany (3,946.6 KTOE), Spain (3.178,1 KTOE) and Italy (2,100.8 KTOE), was among the top Member States with the highest wind power consumption.

The countries with the lowest solar energy consumption include the Baltic countries Estonia and Latvia (not producing any solar energy), Lithuania (5.7

$58 \quad$ Review of International Comparative Management Volume 20, Issue 1, March 2019 
KTOE), and and Finland (3,100 KTOE), this can be explained by the fact that these countries are disadvantaged by their geographic position to benefit from sunlight.

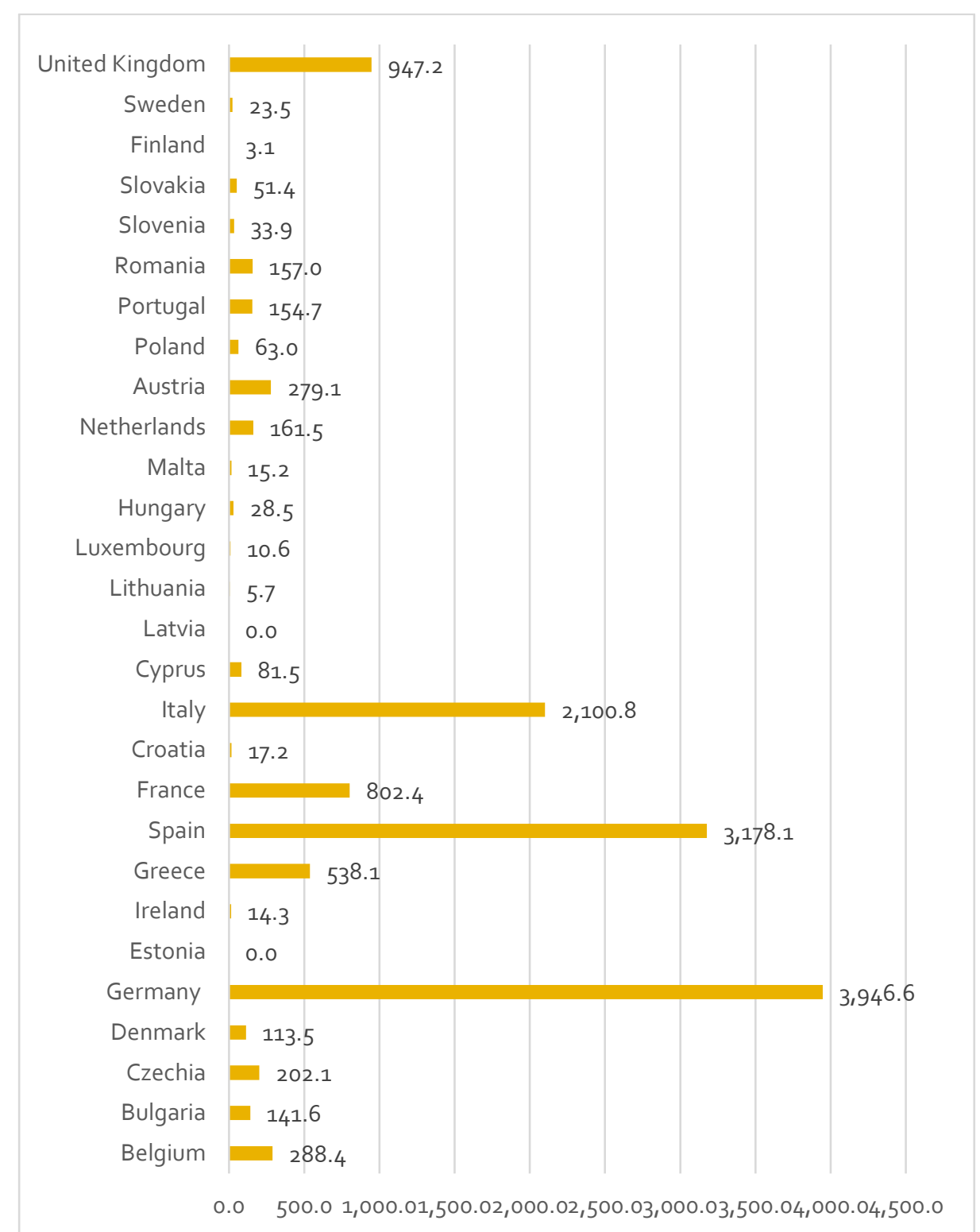

Chart 8 - Gross domestic consumption of solar energy in EU28 in 2016 (KTOE) Source: Eurostat

Concerning the consumption of renewable energy produced from biomass (bioenergy) within the EU Member States in 2016 (Chart no. 9), Germany is a leader with a consumption of 26,174.6 KTOE, representing almost $20 \%$ of the total consumption of bioenergy In the EU28. Another important consumer of bioenergy 
is France $(16,499.0$ KTOE) and Italy $(13,177.3 \mathrm{KTOE})$. It should be noted that in contrast to France, which did not have a significant increase in bioenergy consumption in the period 1990-2016, respectively from 10,414.7 KTOE (1990) to 16,499.0 KTOE (2016), in Italy the consumption of bioenergy increased almost 20 times in 1990 - 2016 period, respectively from $776.7 \mathrm{KTOE}$ (1990) to $13.177,3$ KTOE (2016).

The Member States with the lowest bioenergy consumption in 2016 were: Malta (9.4 KTOE) and Cyprus (50.4 KTOE).

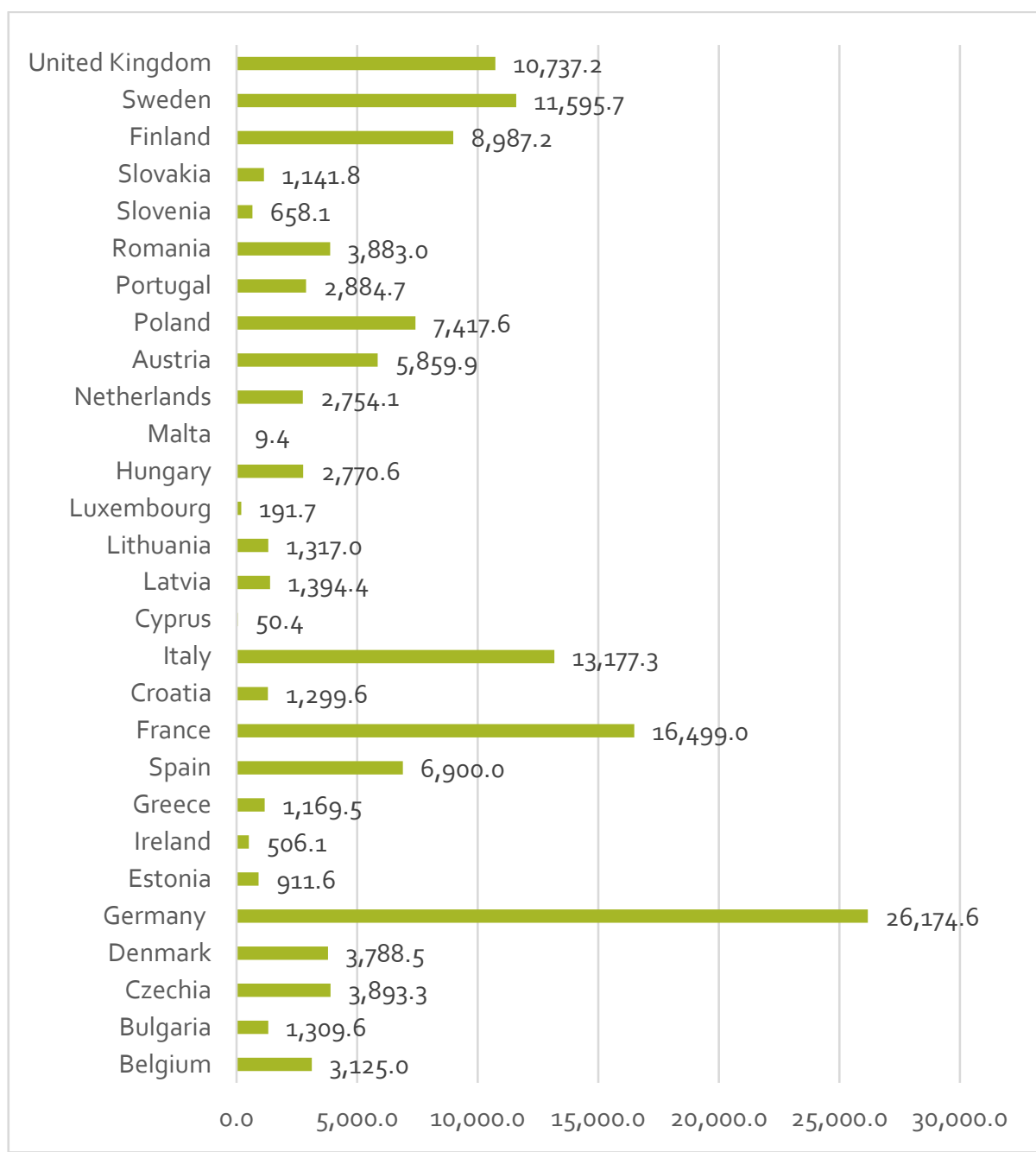

Chart 9 - Gross domestic consumption of bioenergy in EU28 in 2016 (KTOE) Source: Eurostat

In terms of geothermal energy consumption in the EU Member States in 2016 (Chart no. 10), Italy is the first to consume 5.570,600 KTOE, representing about $84 \%$ of total energy consumption. The countries that not producing any

$60 \quad$ Review of International Comparative Management

Volume 20, Issue 1, March 2019 
geothermal energy are: the Czech Republic, Estonia, Ireland, Latvia, Malta, Luxembourg, Sweden and Finland.

Renewable energy can also be analyzed in terms of the three directions in which it can be used, namely for electricity, heating and cooling, and transport.

Regarding the production of electricity from renewable sources, it had a share of $29.6 \%$ of total gross electricity consumption in the EU28 in 2016, the most important source of renewable energy being hydroelectricity and wind power.

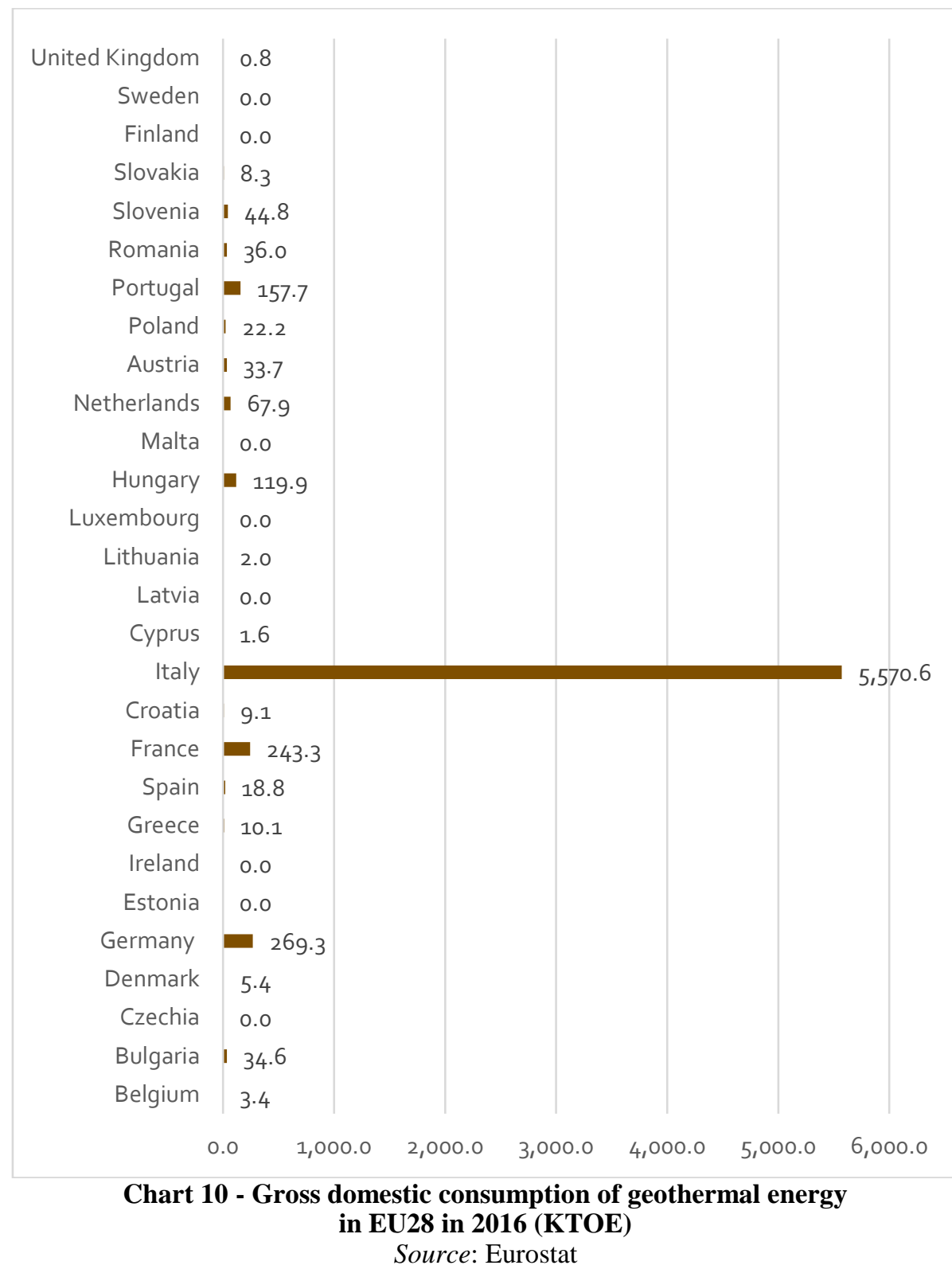

Review of International Comparative Management Volume 20, Issue 1, March 2019 
Regarding the share of renewable energy used for heating and cooling in 2016, it accounted for $19.1 \%$ of total energy consumption in the EU 28.

Regarding the share of energy from renewable sources in transport, in 2016 it represented $7.1 \%$ of the total energy consumption used in transport in the EU 28 and there is a very high chance of reaching the EU28 target, until 2020, the share of energy from renewable sources used in the transport sector representing $10 \%$.

\section{Conclusions}

From the data presented in this paper we can state that the adoption of longterm renewable energy strategies and targets by the EU member states had the expected effect, in the fact that between 1990 and 2016 the gross consumption of renewable energy in EU28 tripled and the share of renewable energy in gross final energy consumption doubled between 2004 and 2016, reaching 17\% (2016), with a high chance of reaching the $20 \%$ target, set by Directive 2009/28 / CE on the promotion of the use of energy from renewable sources.

\section{References}

Directive 2009/28 / CE on the promotion of the use of energy from renewable sources issued on 23 April 2009;

European Commission, the European Economic and Social Committee, the Committee of Regions and the European Investment Bank, "Clean Energy For All Europeans", Brussels, 2016;

European Commission, Communication from the Commission to the European Parliament, the Council, the European Economic and Social Committee and the Committee of the Regions' proposal for a new European Consensus on Development Our world, our dignity, our future ", Strasbourg, 2016;

International Energy Agency, World Energy Investment Outlook Special Report 2014;

International Renewable Energy Agency (IRENA), Rethinking Energy 2017 Acceleratingthe global energy transformation;

International Renewable Energy Agency (IRENA), Energy Prospects for the European Union, 2018;

European Commission, "Guidelines on Hydroelectric Energy Production Requirements in the Context of EU Legislation", Luxembourg, 2018;

European Court of Auditors;

Eurostat;

European Commission, A framework for climate and energy policy in 2020-2030, Brussels, 22.01.2014 COM (2014) 15 final Commission Communication to European Parliament, Council, European Economic and Social Committee and the Committee.

Renewable Energy Policy Network for the 21st Century (REN21), Renewables 2018, Global Status Report

62 Review of International Comparative Management

Volume 20, Issue 1, March 2019 